
interactions in the Mid-Atlantic of the United States

Siwei $\mathrm{Li}^{1^{*}}$, Everette Joseph ${ }^{1,2}$, Qilong Min ${ }^{2}$ and Bangsheng $\mathrm{Yin}^{2}$

1. HOWARD UNIVERSITY

$23556^{\text {TH }}$ STREET NW WASHINGTON, DC 20059

*E-MAIL: SIWEI.LI@HOWARD.EDU

PHONE: 202-865-8678

2. ATMOSPHERIC SCIENCES RESEARCH CENTER, STATE UNIVERSITY OF NEW YORK

\author{
AT ALBANY, ALBANY, NY 12203, USA
}

(1)

12

3

14

15

6

7

18

19

0




\section{Multi-year ground-based observations of aerosol-cloud interactions in the Mid-Atlantic of the United States}

\section{Key words}

Aerosols; aerosol-cloud interaction; cloud droplet effective radius; cloud optical depth; fine particles

\section{Abstract}

The U.S. Mid-Atlantic region experiences a wide variability of aerosol loading and frequent episodes of elevated anthropogenic aerosol loading associated with urban pollution conditions during summer months. In this study, multi-year ground-based observations (2006 to 2010) of aerosol and cloud properties from passive, active and in situ measurements at an atmospheric measurement field station in the Baltimore-Washington corridor operated by Howard University were analyzed to examine aerosol indirect effect on single-layer warm clouds including cloud optical depth (COD), liquid water path (LWP), cloud droplet effective radius (Re) and cloud droplet number concentration $\left(N_{d}\right)$ in this region. A greater occurrence of polluted episodes and cloud cases with smaller $\operatorname{Re}(<7 \mu \mathrm{m})$ were found during the polluted year summers (2006, 2007 and 2008) than the clean year summers (2009 and 2010). The measurements of aerosol particulate matter with aerodynamic diameter $\leq 2.5$ $\mu \mathrm{m}$ (PM2.5) were used to represent the aerosol loading under cloudy conditions. Significant negative relationships between cloud droplet Re and PM2.5 were observed. Cloud cases were separated into clean and polluted groups based on the value of PM2.5. The cloud droplet Re was found proportional to LWP under clean conditions but weakly dependent on LWP under polluted conditions. The $N_{d}$ was proportional to LWP under polluted condition but weakly dependent on LWP under clean conditions. Moreover, the effects of increasing fine aerosol particles on 
modifying cloud microphysical properties were found more significant under large LWP than small LWP in this region.

\section{Introduction}

Investigation of the radiative forcing from aerosol-cloud interactions (RFaci) is crucial to estimates and interpretations of the Earth's changing energy budget (IPCC, 2013). The changes of cloud active aerosols can impact cloud microphysical properties, precipitation and the meteorological and radiance responses of clouds. A growing list of studies with space- and ground-based observations provides convincing evidences of RFaci. By using satellite remote sensing, Han et al. (1998) showed that cloud-droplet concentrations correlate to the cloud condensation nuclei (CCN) at different regions. Feingold et al. (2001) defined the ratio of logarithmic Re and aerosol optical depth (AOD) to represent the RFaci and Feingold et al. $(2003,2006)$ reported the observed RFaci by using ground-based observations of cloud and aerosol properties provided by the Atmospheric Radiation Measurement (ARM) at the Southern Great Plains (SGP) site in Oklahoma. Also with ARM SGP observations Kim et al. $(2003,2008,2012)$ demonstrated the positive relationship between COD and LWP, an inverse relationship between Re and aerosol scattering coefficient and the role of adiabaticity in RFaci. Nzeffe et al. (2008) showed that Re reduced under polluted airmasses for given LWP based on the ground-based observations from Howard University Beltsville Campus (HUBC) facility.

However untangling aerosol effects on clouds and precipitation is still challenging. The extent to which aerosols impact clouds can be different or even opposite under different cloud regimes. The RFaci can be buffered by compensation between different cloud responses to aerosols (Rosenfeld et al., 2014, Stevens and Feingold, 2009). That explains why the statistical effects of aerosol on clouds and precipitation are not agreed upon. But the RFaci is still evident in specific circumstance or regimes (Stevens and Feingold, 2009, Huang et al., 2014 and Pan et al., 2015). The complexity 
of the climate system and the inadequacy of measurements and methodologies have made it very challenging to obtain a more detailed understanding of aerosol-cloud interactions and their effects on climate (McComiskey and Feingold, 2012; Stevens and Feingold, 2009). Part of the challenge is reducing the uncertainty in estimates of RFaci, which as pointed out by McComiskey and Feingold (2012) requires small scale studies. Though field experiments that produce "process scale" observations of aerosol-cloud interaction continue to occur, historically they have been insufficient in number, regional diversity and duration. Current satellite-based sensors can provide global coverage and long-term measurements of aerosols and clouds. However detailed understanding of the RFaci is limited by the large scale, coarse time resolution and inherent limitations in the retrieval algorithms and sensors. Ground-based sensors can provide long-term measurements which are more accurate, stable, smaller scale and higher temporal resolution at specific region of interest compared to satellite sensors. A number of ground-based observation facilities (e.g. ARM sites) have been developed to study aerosol, clouds, precipitation and their influences on global climate change. Independent from ARM the HUBC station $\left(39.054{ }^{\circ} \mathrm{N}\right.$ and $\left.76.877^{\circ} \mathrm{W}\right)$ was established for atmospheric measurements in the U.S. Mid-Atlantic region. This region experiences a wide variability of aerosol loading and frequent episodes of elevated anthropogenic aerosol loading associated with urban pollution conditions during summer months as seen in analyses of derived AOD from Aerosol Robotic Network (AERONET) and a collocated air quality monitoring operated by the Maryland Department of the Environment (MDE) (Holben et al., 1998). Thus, the observations of aerosol and cloud macro- and micro-physical properties in this region are valuable for investigating aerosol-cloud interaction and its impacts on weather and climate. Nzeffe et al. (2008) previously observed aerosol indirect effect based on six months of observations at HUBC site in 2005. This study extends their work to analysis five years (from 2006 to 2010) of ground-based observations of aerosol and cloud properties for systematically 
investigating aerosol impacts on variability of cloud properties including COD, LWP, Re and Nd during summer in this region.

\section{Measurements}

The HUBC facility in Beltsville, MD is situated in a rural-suburban transition region between Washington, $\mathrm{DC}$ and Baltimore, MD urban centers. It has a wide range of sensors deployed to observe atmospheric radiation, surface fluxes, aerosol, cloud properties and other climate and weather processes (Nzeffe et al., 2008).

Among the sensor observations, LWP is determined from a dual frequency ( 23.8 and 31.4 GHz) Microwave radiometer (MWR) (Westwater et al., 2001). The error of the MWR LWP retrieval consists of instrument error, errors associated with the climatological profiles used for the retrieval (given day to day variability of atmospheric temperatures from this climatology), and errors from the absorption model used to develop parameters for the retrieval algorithm (Turner et al., 2007). The errors associated with instrument and climatological profiles used are considered random errors and thus are minimized with increasing sample size of data. The error associated with absorption model is considered a systematic bias and represents the preponderance of the total error. Instrument uncertainty and retrieval errors associated with the climatological profiles and the microwave absorption model results in a total uncertainty of retrieved LWP around $20 \mathrm{~g} / \mathrm{m}^{2}$ (Turner et al., 2007) but the consequence of the systematic error is minimized while relative differences are investigated (e.g cloud droplet Re vs. LWP).

AOD is measured with a Multifilter Rotating Shadowband Radiometer (MFRSR) which is a sensor with a shading band that rotates, measuring global downwelling irradiance, diffuse irradiance and direct beam irradiance calculated from global and diffuse irradiance. More detail on the instrument design can be found in Harrison et al., (1994). The MFRSR is calibrated using data acquired on clear sky days via the Langley regression which is based on linear regressions of the log of direct beam 
134 irradiance versus airmass and the calibration constant $I_{0}$ is used to compute transmittances during cloudy conditions (Harrison et al., 1994; Harrison and Michalsky, 1994). The AOD is retrieved based on the algorithm developed by Harrison and Michalsky (1994). For quality control, the retrieved AOD is compared with AERONET observation at NASA Goddard Space Flight Center (GSFC), around 5 miles southeast of the HUBC facility. High correlation coefficient (0.94) is found between them during the study period (from 2006 January to 2010 December). However retrieval of $A O D$ is not available from any passive remote sensor during cloud periods, so hourly in situ measurements of particulate matter with aerodynamic diameter $\leq 2.5 \mu \mathrm{m}$ (PM2.5) are obtained from samplers operated by the MDE at the HUBC site to estimate aerosol loading under cloudy conditions. Although surface PM2.5 is related more to small particles within boundary layer while AOD presents the total column aerosol loading, surface PM2.5 had a good correlation with AOD in the District of Columbia-Maryland area based on the study of PM2.5-AOD relationship in the United States (Liu et al., 2004). We also found that the measured PM2.5 has a significant positive relationship with MFRSR retrieved AOD with correlation coefficient of 0.63 during clear-sky conditions in summer as seen in Fig. 1.

In situ aerosol size distributions are measured by a Fast Mobility Particle Sizer (FMPS) which was developed based on electrical aerosol spectrometer technology from Tartu University (Tammet et al. 2002; TSI 2006). The FMPS measures particle size distributions in the range from the $6 \mathrm{~nm}$ to $560 \mathrm{~nm}$ with 16 channels per decade every second. However the FMPS measurements at HUBC are only available during the NASA DISCOVER-AQ (a field campaign for deriving information on surface conditions from column and vertically resolved observations relevant to air quality)

159 field campaign in the Baltimore-Washington, D.C., area, in July 2011. So two days of FMPS observations under clear sky with different aerosol loading (polluted day, July $20^{\text {th }}, 2011$ and clean day, July $14^{\text {th }}, 2011$ ) are used to illustrate the differences of detail aerosol size distributions between clean and polluted days in this study. 
A family of retrieval algorithms has been developed for COD and cloud droplet Re retrievals based on MFRSR and MWR (Min and Harrison, 1996; Min et al, 2001; Min et al, 2004, Wang and Min, 2008, Wang and Huang, 2009). Cloud droplet optics is parameterized in terms of average Re and total LWP based on MIE theory (Slingo, 1989; Hu and Stamnes, 1993). COD is retrieved by a Nonlinear Least Squares Method through iterative procedure (Min and Harrison, 1996; Min et al, 2004). Cloud droplet Re is simultaneously retrieved with total LWP observed from MWR while Re is assumed equal to $8 \mu \mathrm{m}$ when measurement of total LWP is not available. The retrieved $\mathrm{Re}$ is an equivalent vertically uniform parameter ("mean $\mathrm{Re}$ "). Compared with eight aircraft in situ vertical profiles (obtained from measurements of Forward Spectra Scattering Probe), the retrieved Re for single-layer warm water clouds agree well with in situ measurements, within 5.5\% (Min et al., 2003). It was shown that a 13\% (LWP, $20 \mathrm{~g} / \mathrm{m}^{2}$ ) uncertainty in observed liquid water path can result in $12.7 \%$ difference in inferred cloud effective radius, on average but only $1.5 \%$ difference in retrieved cloud optical depth. The uncertainty of the LWP measured by MWR is mainly systematic biases (Turner et al., 2007). But the consequence of LWP bias is minimized when considering that the relative difference of Re vs. LWP for clear and polluted conditions is our interest in this study for investigating the RFaci. With the assumption that the clouds in question are adiabatic and $N_{d}$ is vertically constant, the $\mathrm{N}_{\mathrm{d}}$ is obtained from a parameterization in terms of COD and Re (Boers et al., 2006; Bennartz, 2007; Min et al., 2012). Through comparing $N_{d}$ calculated from Moderate Resolution Imaging Spectroradiometer (MODIS) measured COD and Re to in-situ measured $N_{d}$ Min et al. (2012) showed that there was a high correlation between retrieved $\mathrm{N}_{d}$ and in situ measurements with a correlation coefficient of about 0.91 .

Up to three layers cloud-base height were provided by a Vaisala CT25k ceilometer. The CT25k ceilometer is equipped with a pulsed near-infrared diode laser (905 nm) which is located at the site within the vicinity of the MFRSR. The measurement range of this CT25k ceilometer is from 0 to $7500 \mathrm{~m}$ and the vertical resolution is $30 \mathrm{~m}$. 
Retrieval of aerosol extinction coefficients from Mie scattering lidar is improved recently (Li et al., 2015). However the accuracy of aerosol extinction coefficient retrieval from low power lidar CT25K is still challenging and needs more investigation and validation. So in this paper we use surface measurements of PM2.5 instead of AOD.

This investigation is limited to summer months (June, July and August) because the U.S. Mid-Atlantic region experiences the largest variation of aerosol loading due to episodic summertime pollution events. Strong convection that occurs during summer results in more boundary layer clouds, which are tightly coupled with surface aerosols. The inter-seasonal variation of aerosol loading is also large but so is the variation of dynamical and thermodynamic conditions that dominate cloud micro- and macro- physical properties. The latter effect on cloud properties could complicate the analysis of aerosol cloud interaction on this scale. For this reason the study is confined to the summer months. Since the domain of the field of view of an upward looking MFRSR is about a couple of kilometers under lower level cloud condition (Min et al., 2001), following Min et al. (2003) and Nzeffe et al. (2008), cloud properties retrieved from MFRSR are 5 minutes averaged and only those cases of single-layer clouds continuously lasting longer than 30 minutes were used for this study. To increase the likelihood that the aerosols at the cloud base can be represented by the surface measurements, we confine the observations to low clouds with cloud base height is lower than $3 \mathrm{~km}$. For optical thin clouds the radiative flux is sensitive to the small changes of LWP (Min and Duan, 2005) and consequently the Re retrieved from combination of MWR LWP and MFRSR COD has relatively larger uncertainties, mainly due to the uncertainty of MWR measurements (Min et al., 2003). So cases with LWP smaller than $40 \mathrm{~g} / \mathrm{m}^{2}$ are removed in the data analysis for this study. Clear sky and broken clouds are also removed by using MFRSR measured direct beam (derived total optical depth smaller than 5), MFRSR estimated cloud-fraction (smaller than 90\%) (Min et al., 2008) and ceilometer undetected clouds. Possible precipitation are avoided by screening clouds with LWP $>180 \mathrm{~g} / \mathrm{m}^{2}$, 
Re>15 $\mu \mathrm{m}$ andceilometer detected rain/cloud near surface (lower than $30 \mathrm{~m}$ ). Ceilometer derived cloud layers and cloud base height are used to screen out high clouds (higher than $3 \mathrm{~km}$ ) and possible multi-layer clouds. In the summer of this region air temperature is usually around $0{ }^{\circ} \mathrm{C}$ at the height of $5 \mathrm{~km}$ and above $-10{ }^{\circ} \mathrm{C}$ at the height of $6 \mathrm{~km}$ at daytime from radiosonde measurements. Cloud top heights are seldom higher than $6 \mathrm{~km}$ when cloud base height is below $3 \mathrm{~km}$ except for those deep convective clouds which are already removed in this study through the threshold of LWP. So the ice particles contamination can be neglected.

\section{Results and discussion}

3.1 Comparison of aerosol, cloud properties in polluted and clean years

Based on the daily average AOD, the summer average AOD in years 2006-2010 were $0.50,0.60,0.40,0.35$, and 0.36 , respectively, (Fig. 2a). The probability distribution of daily $A O D$ shows that more frequent episodes of high aerosol loading ( $A O D>0.50$ ) occur during the summers of year 2006, 2007 and 2008 as compared to those in year 2009 and 2010 (figure 2b). The measurements of PM2.5 from MDE at HUBC site show that the average PM2.5 values in the summer of year 2006, 2007 and 2008 are $20,20.5$ and $18 \mu \mathrm{g} / \mathrm{m}^{3}$ respectively which are larger than that in the summers of year 2009 and 2010 (14 and $16 \mu \mathrm{g} / \mathrm{m}^{3}$ respectively) (figure 2c). Figure $2 \mathrm{~d}$ shows that a greater occurrence of polluted cases (PM2.5 larger than $30 \mu \mathrm{g} / \mathrm{m}^{3}$ ) occur in year 2006, 2007 and 2008 compared to that in year 2009 and 2010. Thereafter the year 2006, 2007 and 2008 are denoted as polluted years while the year 2009 and 2010 are denoted as clean years for convenience.

The retrievals of AOD are commonly based on measurements of spectral extinction of solar radiation due to aerosol scattering and absorption in the atmospheric column. Passive instrument, such as the MFRSR, cannot readily discern AOD from COD under cloudy conditions. So in this study the synchronous PM2.5 measurements are used to represent the aerosol situation under clouds given that $A O D$ 
measurements are not available under cloudy condition. There are a total of 9 cloudy or partly cloudy days for which low single-layer clouds lasting longer than 30 minutes with PM2.5 larger than $20 \mu \mathrm{g} / \mathrm{m}^{3}$ are observed and 11 similar days with PM2.5 smaller than $20 \mu \mathrm{g} / \mathrm{m}^{3}$ in polluted year summers. The $20 \mu \mathrm{g} / \mathrm{m}^{3}$ is chosen based on mean value and number of cases in polluted years. For similar 23 days in clean year summers, PM2.5 are smaller than $20 \mu \mathrm{g} / \mathrm{m}^{3}$ for all cloud cases. The average PM2.5 under cloudy conditions in the polluted years is about $24.8 \mu \mathrm{g} / \mathrm{m}^{3}$ while it is only $11.1 \mu \mathrm{g} / \mathrm{m}^{3}$ in the clean years. The probability distribution shows that there are more than $60 \%$ cloud cases with surface PM2.5 value larger than $20 \mu \mathrm{g} / \mathrm{m}^{3}$ in the polluted years while there is no cloud case with PM2.5 value larger than 20 $\mu \mathrm{g} / \mathrm{m}^{3}$ found in the clean years (figure 3a). The average LWP for clouds in the polluted years $\left(124.51 \mathrm{~g} / \mathrm{m}^{2}\right)$ is around $10 \%$ larger than that in clean years $(114.53$ $\mathrm{g} / \mathrm{m}^{2}$ ) and that is due to the more frequent cases of LWP larger than $150 \mathrm{~g} / \mathrm{m}^{2}$ (figure $3 b)$. The average COD in the polluted years (25.37) is about $25 \%$ larger than that in the clean years (20.39). There are about $25 \%$ cloud cases with COD larger than 30 in the polluted years while there are only $7 \%$ cloud cases with COD larger than 30 in the clean years (figure $3 \mathrm{~b}$ ). In the polluted years the distribution of Re shifts to the smaller value and the average $\operatorname{Re}(7.97 \mu \mathrm{m})$ is about $13 \%$ smaller compared to that in the clean years $(9.12 \mu \mathrm{m})$.

To assess the difference of microphysical properties of clouds with same LWP during the polluted and clean years, the COD and Re values are sorted into 7 bins of LWP with $20 \mathrm{~g} / \mathrm{m}^{2}$ bin widths. The mean COD and Re are computed and plotted with the arithmetic mean of each bin. Error bars represent the $95 \%$ confidence levels of the mean value. Over the entire LWP range, the mean COD observed during the polluted years is larger than that during the clean years by as much as 5 (Fig. 4a) and the mean Re is less during the polluted years than that during the clean years by as much as $1.2 \mu \mathrm{m}$ (Fig. 4b). The mean COD and Re increase with increasing LWP during both the polluted and clean years and the differences of the mean COD, Re during the 
277 polluted and clean years (COD polluted - COD clean, Re clean - Re polluted) are also 278 increased with increasing of LWP.

281 To investigate aerosol indirect effects on cloud microphysical properties, the measurements of Re are plotted along with the value of PM2.5 in figure 5a. Figure 5a shows a negative relationship between Re and PM2.5 with the correlation coefficient of -0.382 for the entire 5 year summer observations. Individually, the relationships of Re and PM2.5 in polluted years and clean years are all negative with the correlation coefficient of -0.285 and -0.197 respectively (figure $5 b, c)$. The correlations are all statistical significant through T-test analysis (Wilks, 1995). The entire 5 year summer observations are segregated into clean group (PM2.5 $<20 \mu \mathrm{g} / \mathrm{m}^{3}$, number of data: 631) and polluted group (PM2.5 >= $20 \mu \mathrm{g} / \mathrm{m}^{3}$, number of data: 367). The observed pairs of Re and LWP are shown in Figure 6a for clean and polluted groups. It is shown that Re increases with increasing LWP under clean conditions while Re deceases with increasing LWP under polluted condition. When LWP is large $\left(>120 \mathrm{~g} / \mathrm{m}^{2}\right)$ the Re is much larger under clean conditions than under polluted conditions for most cases. When LWP is small $\left(<100 \mathrm{~g} / \mathrm{m}^{2}\right)$ the Re is similar or even smaller under clean conditions than under polluted conditions. Cloud droplets compete with each other as they grow through water diffusion. There is less competition among droplets at lower cloud condensation nuclei (CCN) concentration and thus a wider spectrum of droplets is activated. This is in contrast to higher CCN concentration where the increased competition limits the spectral range of droplet activation.

300 Figure 6a shows that there is a significant positive relationship between $N_{d}$ and 301 LWP with correlated coefficient of 0.612 under polluted conditions and a slightly 302 negative relationship with correlated coefficient of -0.15 under clean conditions. 303 Under clean conditions aerosol particle number concentration $\left(N_{a}\right)$ is less, most 304 aerosol particles are activated into cloud droplets with sufficient water supply which 
means $N_{d}$ is limited by $N_{a}$, so $N_{d}$ is nearly independent of LWP and the droplet growth process dominates in the development of cloud. On the other hand, under polluted conditions with abundant $N_{a}$, there are more potential aerosol particles that can be activated into cloud droplets with sufficient water supply and strong updraft velocity. So the $N_{d}$ is observed increasing with increasing LWP under polluted conditions. Larger number of activated droplets increase cloud droplet concentration but then cause relatively small Re due to the increased competition for available water vapor. It is also noticed that the $N_{d}$ under polluted conditions is larger than under clean condition for most cases when LWP is large (larger than 120 $\mathrm{g} / \mathrm{m}^{2}$ ) but is similar or even smaller than that under clean conditions when LWP is small (smaller than $100 \mathrm{~g} / \mathrm{m}^{2}$ ). Those are consistent with the aerosol-limited regime and updraft-limited regime from the study by Reutter et al., (2009) which simulated cloud droplet formation under different regimes based fine aerosol particles. In the aerosol-limited regime that is characterized by a relative high updraft velocity and water vapor supersaturation which implies large LWP, $N_{d}$ is directly proportional to $N_{a}$. The high updraft velocity and water vapor supersaturation can activate nearly all aerosol particles. In the updraft-limited regime that is characterized by relative low updraft velocity and water vapor supersaturation which implies small LWP, $N_{d}$ is weakly dependent on $N_{a}$. Under extreme conditions with very low updraft velocity but very large $N_{a}$, supersaturation can be quenched by the cost of water taken by aerosol particles. So the $N_{d}$ could be smaller under polluted conditions than that under clean conditions when LWP is small. Through cloud parcel model simulation, Reutter et al. (2009) indicated that the variability of $N_{a}$ in the Aitken and accumulation mode mostly dominates the variability of initial $N_{d}$ except at low supersaturations in updraft limit regimes. 
331 To know aerosol size under polluted condition in this region, the in situ observations 332 of aerosol size distributions from a FMPS at HUBC during DISCOVER AQ field 333 campaign under clean and polluted conditions in this region are compared (Fig. 7). 334 On a polluted day (July $20^{\text {th }}, 2011$ ), the total number concentration of aerosol is much higher than that on a clean day (July $14^{\text {th }}, 2011$ ) and it is almost entirely due to the higher number concentration of aerosol particles in Aitken and accumulation mode. Although the field campaign only last one month at HUBC the detailed aerosol size distributions observation gave us a sense that the increase of aerosol particles in this area may be mainly due to the increase of fine particles. Aerosol optical properties are related to aerosol size distribution. As an aerosol size indicator, aerosol angstrom coefficient generally decreases with increasing aerosol size. The long-term observations show that the observed hourly angstrom coefficients which are calculated from MFRSR measured AOD at $415 \mathrm{~nm}$ and $860 \mathrm{~nm}$ have significant positive relationship $(\mathrm{P}<0.0001)$ with hourly PM2.5 (Fig. 8). This correlation implies that an increase of PM2.5 value is associated with an increase of total column fine particles over this region given that angstrom coefficient is calculated from column AOD at different wavelength.

In the updraft-limited regime with low supersaturations, supersaturation can be quenched by the cost of water taken by large amount of fine aerosol particles. So the $N_{d}$ under polluted conditions for which fine aerosol particles dominate appears to be similar or even smaller than the $N_{d}$ under clean conditions when LWP is small

352 (smaller than $100 \mathrm{~g} / \mathrm{m}^{2}$ in this study). Within the aerosol-limited regime with large 353 updraft velocity and supersaturation, $N_{d}$ is larger under polluted condition 354 because more aerosol particles can be activated to cloud droplets. 


\section{Conclusions}

358 Long-term ground-based observations of aerosol and cloud optical properties from HUBC facility are employed to show aerosol impacts on cloud properties in the Mid-Atlantic in the United States. The retrieved AOD at the HUBC site agrees well with that from a nearby AERONET site and closely correlates with PM2.5 measured at the site. The distributions of daily mean AODs and PM2.5 show that there were a greater occurrence of polluted episodes in year 2006, 2007 and 2008 as compared to year 2009 and 2010. The statistical analysis of collocated measurements of PM2.5 and cloud properties shows that in the polluted years there are more cloud cases with larger PM2.5 values, smaller Re and larger COD. Within the same LWP bins, the mean COD is evidently larger and the mean Re is smaller in the polluted years. The Re is found inversely related to PM2.5 with correlated coefficient of -0.285 and -0.197 in polluted years and clean years respectively. For all cases, the correlation coefficient between Re and PM2.5 is -0.382 . The entire 5 year summer observations of cloud properties are segregated into polluted and clean groups based on PM2.5 value ( $>=20 \mu \mathrm{g} / \mathrm{m}^{3},<20 \mu \mathrm{g} / \mathrm{m}^{3}$ respectively). The variability of Re and $N_{d}$ with increasing LWP are found different under polluted and clean conditions. Under polluted conditions, Re slightly deceases with increasing LWP while $N_{d}$ significantly increases with increasing LWP. Under clean conditions, Re increases with increasing LWP while $N_{d}$ is nearly independent of LWP. The $N_{d}$ is larger under polluted conditions than that under clean conditions when LWP is large $\left(>120 \mathrm{~g} / \mathrm{m}^{2}\right)$ but similar or even smaller than that under clean conditions when LWP is small $(<100$ $\mathrm{g} / \mathrm{m}^{2}$ ). Simulations done by Reutter et al., (2009) suggest this phenomenon is consistent with that fine aerosol particles impacts on $N_{d}$ in aerosol-limit regime with high supersaturation and in updraft-limit regime with low supersaturation (Reutter et al., 2009). The measurements of aerosol size distribution and angstrom coefficient show that the increase of aerosol particles in the summer of Baltimore-Washington, DC region is mainly due to the increase of fine particles. Under clean conditions, the 
400

401

402

403

404

405

406

407

408

409

$N_{d}$ is limited by $N_{a}$, so increasing LWP is mainly attributed to droplet growth. Under polluted conditions, more new cloud droplets can be activated with high supersaturation and the increase of $N_{d}$ dominates over cloud droplets growth. But with lower supersaturation, abundant aerosol particles would take up water and supersaturation could be reduced to a level which prevents activation of cloud droplets from fine (Aitken and accumulation) mode aerosol particles. So the $N_{d}$ and

Re are strongly impacted by $N_{a}$ in fine mode under high supersaturation but weakly impacted by $N_{a}$ in fine mode under lower supersaturation. Analysis based on the long-term observations including diverse dynamical and aerosol regimes at HUBC site can provide climate assessment of RFaci in the mid-Atlantic corridor, where frequent severe pollution episodes occur.

Acknowledgements: This work is supported by the National Oceanic and Atmospheric Administration, Educational Partnership Program, U.S. Department of Commerce, under Agreement No. NA11SEC4810003.

\section{References}

Ackerman AS, Kirkpatrick MP, Stevens DE, and Toon OB. 2004. The impact of humidity above stratiform clouds on indirect aerosol climate forcing, Nature, $\mathbf{4 3 2}$, 1014-1017, doi:10.1038/nature03174.

Albrecht BA. 1989. Aerosol, cloud microphysics, and fractional cloudiness, Science, 245, 1227-1230, doi:10.1126/science.245.4923.1227. 
410 Brioude J., et al. 2009. Effect of biomass burning on marine stratocumulus clouds off 411 the California coast, Atmos. Chem. Phys ., 9 , 8841 - 8856, doi: 412 10.5194/acp-9-8841-2009.

413

414 Bennartz R. 2007. Global assessment of marine boundary later cloud droplet number 415 concentration from satellite, J. Geophys. Res., 112, D02201, doi: $416 \quad 10.1029 / 2006 J D 007547$.

417

418 Boers R, Acarreta JA, Gras JL. 2006. Satellite monitoring of the first indirect aerosol 419 effect: Retrieval of the droplet con-centration of water clouds, J. Geophys. Res., 111, 420 D22208, doi:10.1029/2005JD006838.

421

422 Coakley JA, Walsh CD. 2002. Limits to the aerosol indirect radiative effect derived 423 from observations of ship tracks, J. Atmos. Sci. , 59, $668-680$, doi: 424 http://dx.doi.org/10.1175/1520-0469(2002)059<0668:LTTAIR>2.0.CO;2 425

426 Feingold G, Remer LA, Ramaprasad J, Kaufman YJ. 2001. Analysis of smoke impact on 427 clouds in Brazilian biomass burning regions: An extension of Twomey's approach, J. 428 Geophys. Res., VOL. 106, NO. D19, PAGES 22,907-22,922

429

430 Feingold G, Eberhard W, Veron D, Previdi M. 2003. First measurements of the 431 Twomey indirect effect using ground-based remote sensors, Geophys. Res. Lett., 432 30(6), 1287, doi:10.1029/2002GL016633.

433

434 Feingold G, Furrer R, Pilewskie P, Remer LA, Min Q, Jonsson H. 2006. Aerosol indirect 435 effect studies at southern Great Plains during the May 2003 intensive operations 436 period, J. Geophys. Res., 111, D05S14, doi:10.1029/2004JD005648. 
438 Han Q, Rossow WB, Lacis AA. 1994. Near global survey of effective droplet radii in 439 liquid water clouds using ISCCP data. J. Climate, 7, 465-497.

440

Han Q, Rossow WB, Chou J, Welch RM. 1998. Global variation of cloud effective

442 droplet concentration of low-level clouds. Geophys. Res. Lett., 25, 1419-1422.

443

Harrison L, and Michalsky J. 1994. Objective algorithms for the retrieval of optical

445 depths from ground-based measurements, Appl. Opt., 33, 5126- 5132.

446

Harrison L, Michalsky J, Berndt J. 1994. Automated multifilter rotating shadow-band

448 radiometer: An instrument for optical depth and radiation measurements, Appl. Opt., 33, $5118-5125$.

450

Holben BN, Eck TF, Slutsker I, Tanré D, Buis JP, Setzer A, Vermote E, Reagan JA,

Kaufman YJ, Nakajima T, Lavenu F, Jankowiak I, Smirnov A. 1998. AERONET-A federated instrument network and data archive for aerosol characterization, Remote Sens. Environ., $66,1-16$.

455

Hu, Y. X., and K. Stamnes, An accurate parameterization of the radiative properties of 457 water clouds suitable for use in climate models, J. Clim., 6, 728-742, 1993.

458

Huang J., T. Wang, W. Wang, Z. Li, and H. Yan. 2014. Climate effects of dust aerosols 460 over East Asian arid and semiarid regions, J. Geophys. Res. Atmos., 119, 11,398-11,416, doi:10.1002/2014JD021796.

462

Kim BG, Schwartz SE, Miller MA, Min Q. 2003. Effective radius of cloud droplets by 464 ground-based remote sensing: Relationship to aerosol, J. Geophys. Res., 108(D23), 465 4740, doi:10.1029/2003JD003721. 
467 Kim BG, Miller MA, Schwartz SE, Liu Y, Min Q. 2008. The role of adiabaticity in the 468 aerosol first indirect effect, J. Geophys. Res., 113, D05210, 469 doi:10.1029/2007JD008961.

470

471 Kim Y, Kim B, Miller M, Min Q, Song C. 2012. Enhanced aerosol-cloud relationships 472 in more stable and adiabatic clouds, Asia-Pacific Journal of Atmospheric Sciences, 48, 473 Issue 3, pp 283-293, doi: 10.1007/s13143-012-0028-0

474

475 Lebsock MD, Stephens GL, Kummerow C. 2008. Multisensor satellite observations of 476 aerosol effects on warm clouds, J. Geophys. Res., 113, D15205, 477 doi:10.1029/2008JD009876.

478

Lee SS, Penner JE, Saleeby SM. 2009. Aerosol effects on liquid-water path of thin 480 stratocumulus clouds, J. Geophys. Res., 114, D07204, doi:10.1029/2008JD010513.

481

482

Li C, Pan Z, Mao F, Gong W, Chen S, Min Q. 2015. De-noising and retrieving algorithm 483 of Mie lidar data based on the particle filter and the Fernald method. Opt 484 Express. 2015 Oct 5;23(20):26509-20, doi: 10.1364/OE.23.026509.

485

486

Liu, Y., Park, R. J., Jacob, D. J., Li, Q. B.; Kilaru, V., Sarnat, J. A. 2005. Mapping annual 487 mean ground-level PM2.5 concentrations using Multiangle Imaging 488 Spectroradiometer aerosol optical thickness over the contiguous United States. J. 489 Geophys. Res, 109, D22206, doi: 10.1029/2004JD005025.

490

491 McComiskey A., Feingold G. 2012. The scale problem in quantifying aerosol indirect 492 effects, Atmos. Chem. Phys., 12, 1031-1049, doi:10.5194/acp-12-1031-2012. 493 
Min Q, Harrison L. 1996. Cloud properties derived from surface MFRSR measurements and comparison with GOES results at the ARM SGP site, Geophys. Res. Lett. , 23 , $1641-1644$.

497

Min, Q., L. C. Harison, and E. Clothiaux (2001), Joint statistics of photon path length and cloud optical depth: Case studies, J. Geophys. Res., 106, 7375-7386.

500

Min Q, Duan M, Marchand R. 2003. Validation of surface retrieved cloud optical 502 properties with in situ measurementsat the Atmospheric Radiation Measurement Program (ARM) South Great Plains site, J. Geophys. Res., 108(D17), 4547,doi:10.1029/2003JD003385, 2003.

505

Min Q, Duan M. 2005. Simultaneously retrieving cloud optical depth and effective 507 radius for optically thin clouds, J. Geophys. Res., 110, D21201, 508 doi:10.1029/2005JD006136.

509

Min, Q., T. Wang, C. N. Long, and M. Duan. 2008, Estimating fractional sky cover 511 from spectral measurements, J. Geophys. Res., 113, D20208, doi:10.1029/ $512 \quad 2008 J D 010278$.

513

Min Q, Joseph E, Lin Y, Min L, Yin B, Daum PH, Kleinman LI, Wang J, Lee YN. 2012. Comparison of MODIS cloud microphysical properties with in-situ measurements

516 over the Southeast Pacific, Atmos. Chem. Phys., 12, 11261-11273, 517 www.atmos-chem-phys.net /12/11261/2012/doi:10.5194/acp-12-11261-2012 518

Nzeffe F., Joseph E, Min Q. 2008. Surface-based observation of aerosol indirect 521 effect in the Mid-Atlantic region, Geophys. Res. Lett., 35, L22814, doi: 10.1029/2008GL036064. 
Pan Z., W. Gong, F. Mao, J. Li, W. Wang, C. Li, and Q. Min. 2015, Macrophysical and optical properties of clouds over East Asia measured by CALIPSO, J. Geophys. Res. Atmos., 120, 11,653-11,668, doi:10.1002/2015JD023735.

Rosenfeld D, Sherwood S, Wood R, Donner L. 2014. Climate effects of aerosol-cloud interactions. Science 343:379-380.

Rogers RR, Yau, MK. 1989. A Short Course in Cloud Physics, Int. Ser. Nat. Philos, 113 : 290.

Slingo, A., A GCM parameterization for the shortwave radiative properties of water clouds, J. Atoms. Sci., 46, 1419-1427, 1989.

Stevens B, Feingold G. 2009. Untangling aerosol effects on clouds and precipitation in a buffered system, Nature, 461 , doi:10.1038/nature08281.

Storelvmo T, Kristjánsson JE, Myhre G, Johnsrud M, Stordal F. 2006. Combined observational and modeling based study of the aerosol indirect effect, Atmos. Chem. Phys., 6, 3583-3601, doi:10.5194/acp-6-3583-2006.

Tammet, H., Mirme, A., and Tamm, E. 2002. Electrical Aerosol Spectrometer of Tartu University, Atmos. Res. 62:315-324.

TSI. 2006. Fast Mobility Particle Sizer Spectrometer; Operation and Service Manual, TSI Incorporated, Shoreview, MN, USA.

Turner DD, Vogelmann AM, Johnson K, Miller M, Austin RT, Barnard JC, Flynn C, Long C, McFarlane SA, Cady-Pereira K, Clough SA, Chiu JC, Khaiyer MM, Liljegren J, Lin B, Minnis P, Marshak A, Matrosov SY, Min Q, O'Hirok W, Wang Z, Wiscombe W. 
552 2007.Thin liquid water clouds: Their importance and our challenge. Bull. Am.

553 Meteorol. Soc., 88(2), 177-190.

554

555 Twohy CH, Petters MD, Snider JR, Stevens B, Tahnk W, Wetzel M, Russell L, Burnet F.

556 2005. Evaluation of the aerosol indirect effect in marine stratocumulus clouds:

557 Droplet number, size, liquid water path, and radiative impact, J. Geophys. Res., 110,

558 D08203, doi:10.1029/2004JD005116.

559

560 Twomey S. 1974. Pollution and the planetary albedo, Atmos. Environ., 8, 1251- 1256.

561

562 Twomey S. 1977. Influence of pollution on shortwave albedo of clouds. J. Atmos. Sci.,

$563 \quad 34,1149-1152$.

564

565

Wang T and Q. Min. 2008. Retrieving optical depths of optically thin and

566 mixed-phase clouds from MFRSR measurements, J. Geophys. Res. 113, D19203

567

Wang $T$ and J. Huang . 2009. A method for estimating optical properties of dusty

568 cloud, Chin. Opt. Lett., 7(5), 368-372, doi:10.3788/COL20090705.0368

569

570 Westwater ER, Han Y, Shupe MD, Matrosov SY. 2001. Analysis of integrated cloud

571 liquid and precipitable water vapor retrievals from microwave radiometers during

572 the Surface Heat Budget of the Arctic Ocean project, J. Geophys. Res., 106, 32,019-

$57332,030$.

574

575

576

Wilks DS. 1995. Statistical Methods in the Atmospheric Sciences, Academic, San

577

578 Wood R, Hartmann DL. 2006. Spatial variability of liquid water path in marine

579 boundary layer clouds: The importance of mesoscale cellular convection. J. Climate, $580 \quad 19,1748-1764$. 
582

583

584

585

586

587

588

589

590

591

592

593

594

595

596

597

598

599

600

601

602

603

604

605

606

607

608

609

Zheng X, Albrecht B, Minnis P, Ayers K, Jonson H. 2010. Observed aerosol and liquid water path relationships in marine stratocumulus, Geophys. Res. Lett., 37, L17803, doi:10.1029/2010GL044095.

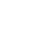


610

611

612

613

614

615

616

617

618

619

620

Fig. 6. (a) The relationship between Re and LWP under different PM2.5 value, and (b) the relationship between cloud droplets number concentration and liquid water path under different PM2.5 value.

Fig. 7. FMPS measured aerosol size distribution on the polluted day (July 20th, 2011) and clean day (July 14th, 2011) during DISCOVER AQ field campaign.

Fig. 8. The relationship of 5 years summer time hourly average Angstrom coefficient and PM2.5.

\section{Figures}

Fig. 1.

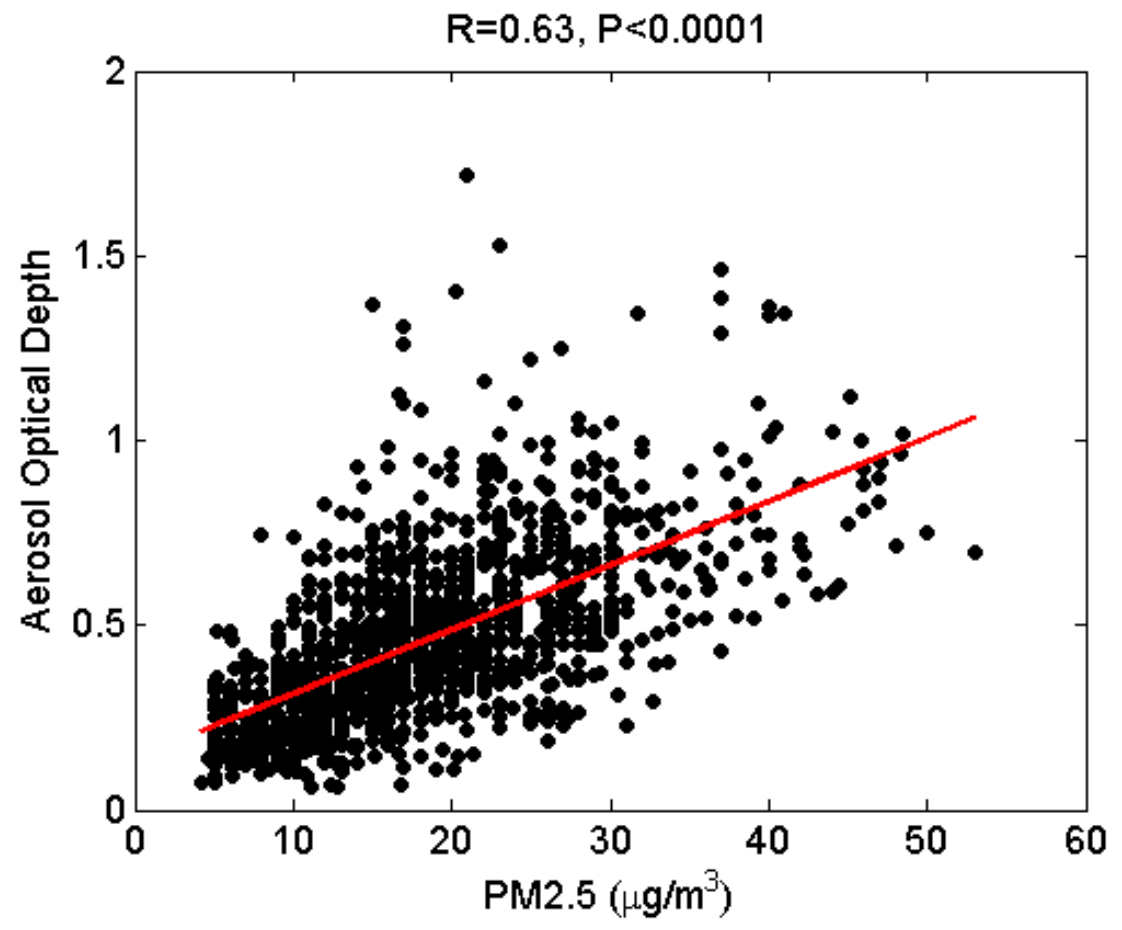

622 Fig. 1. The relationship of hourly average AOD and PM2.5 based on 5 years (2006 to 623 2010) summer time clear sky measurements.

624 

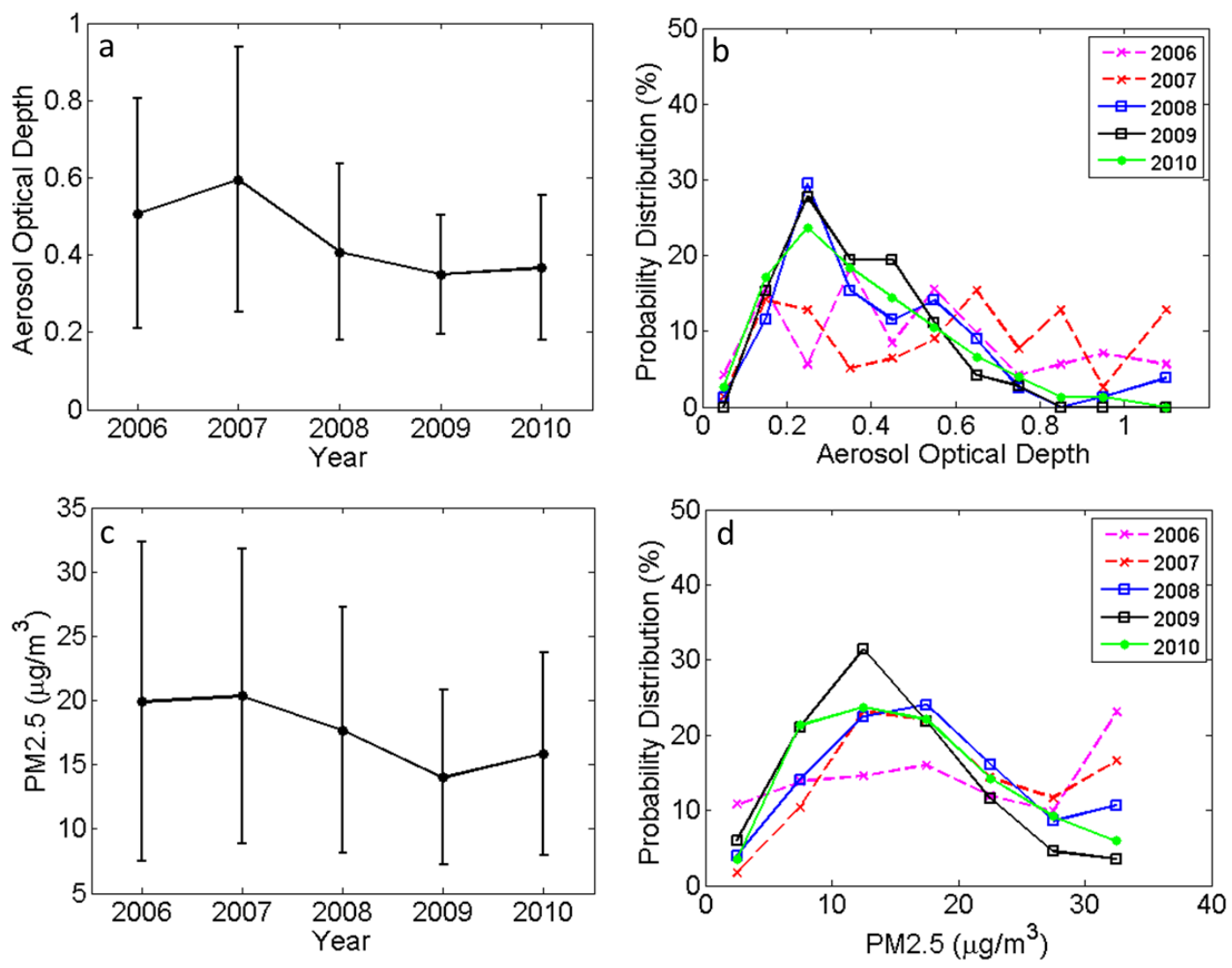

627 Fig. 2. The aerosol properties for each year. (a)Summer averaged AOD with standard 628 deviation; (b) distribution of daily AOD measurements (bins: interval is 0.1 when 629 AOD is from 0 to 1.0 and the last bin is AOD >=1.0); (c) summer averaged PM2.5 with 630 standard deviation and (d) distribution of hourly PM2.5 measurements (bins: interval 631 is $5 \mu \mathrm{m}$ when PM2.5 is from 0 to $30 \mu \mathrm{g} / \mathrm{m}^{3}$ and the last bin is PM2.5 >=30 $\mu \mathrm{g} / \mathrm{m}^{3}$ ). 

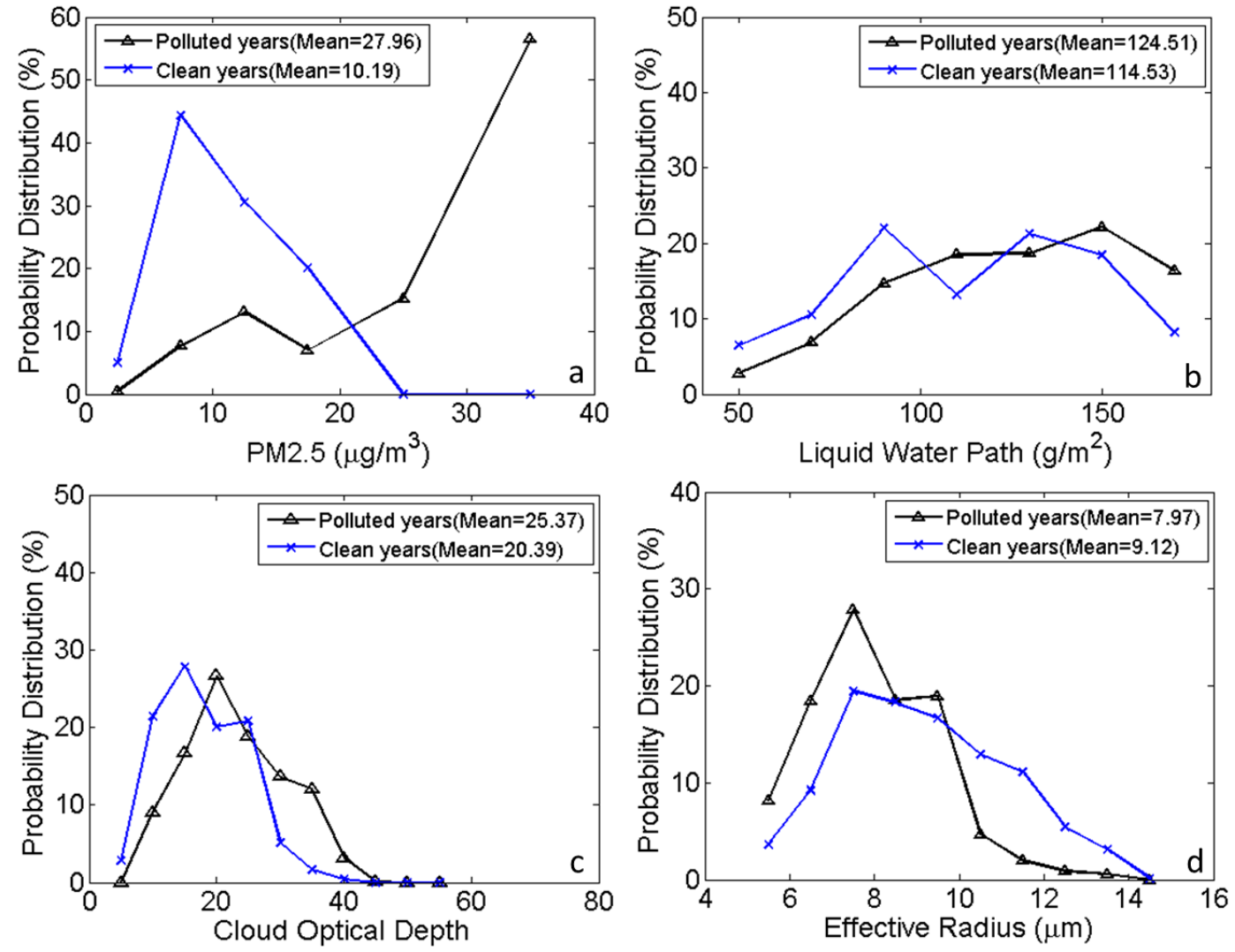

634 Fig. 3. The distributions of PM2.5 and cloud properties during polluted years and 635 clean years. (a) PM2.5; (b)LWP; (c) COD and (d)Re. 

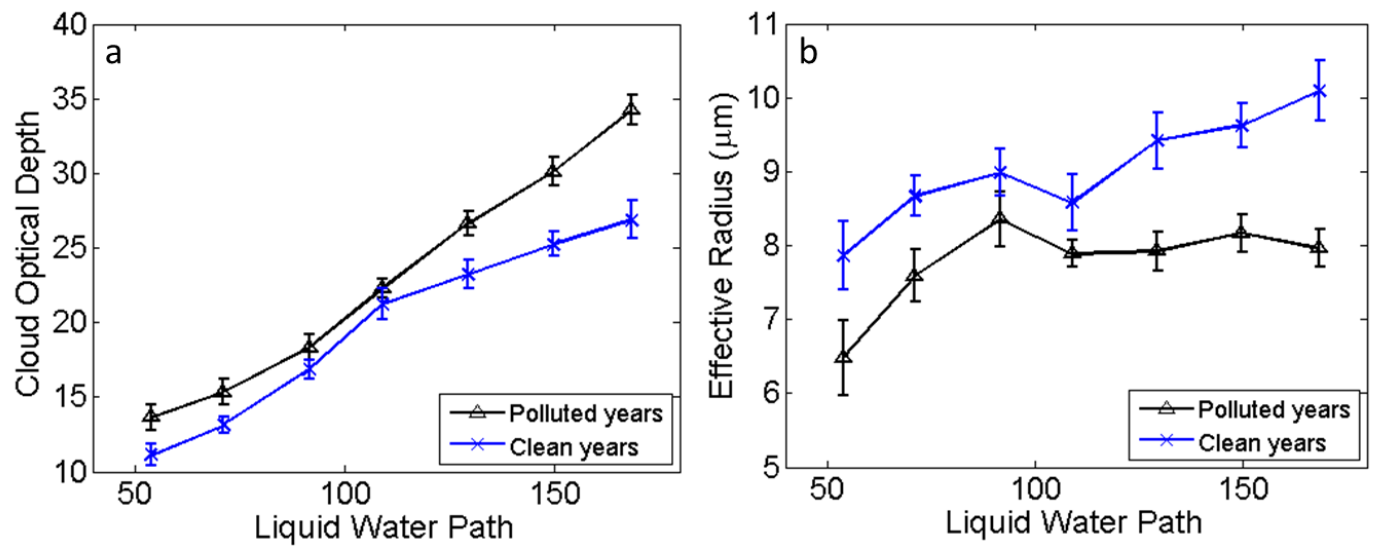

641 Fig. 4. The comparison of mean COD, mean Re between during polluted and clean 642 years. (a) Mean COD VS. LWP, (b) mean Re VS. LWP. Error bars represent the 95\% 643 confidence level.

644

645

646

647

648

649

650

651

652

653 

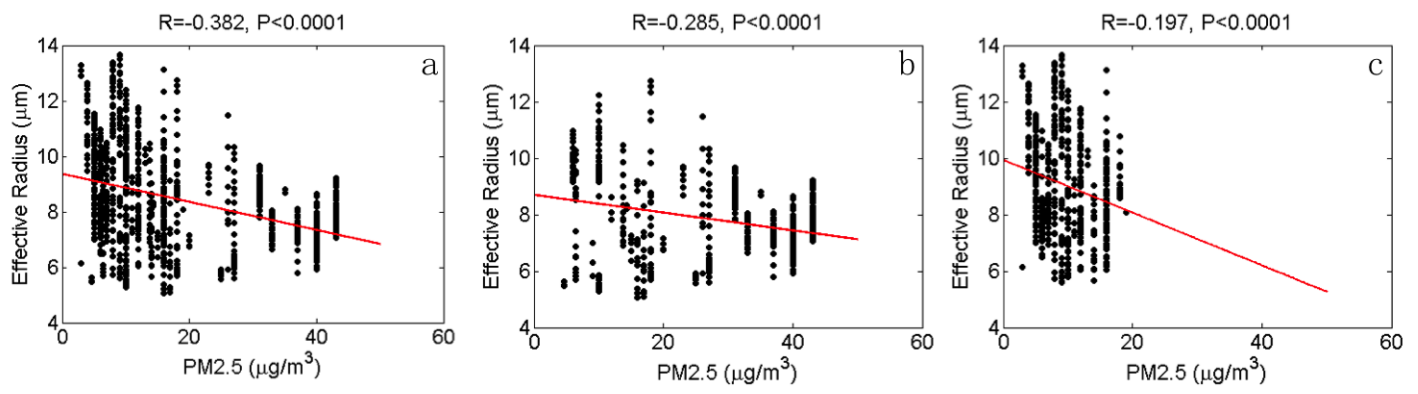

655 Fig. 5. The relationship between Re and PM2.5. (a)For entire five years; (b)for 656 polluted years and (c)for clean years.

657

658

659

660

661

662

663

664

665

666

667 

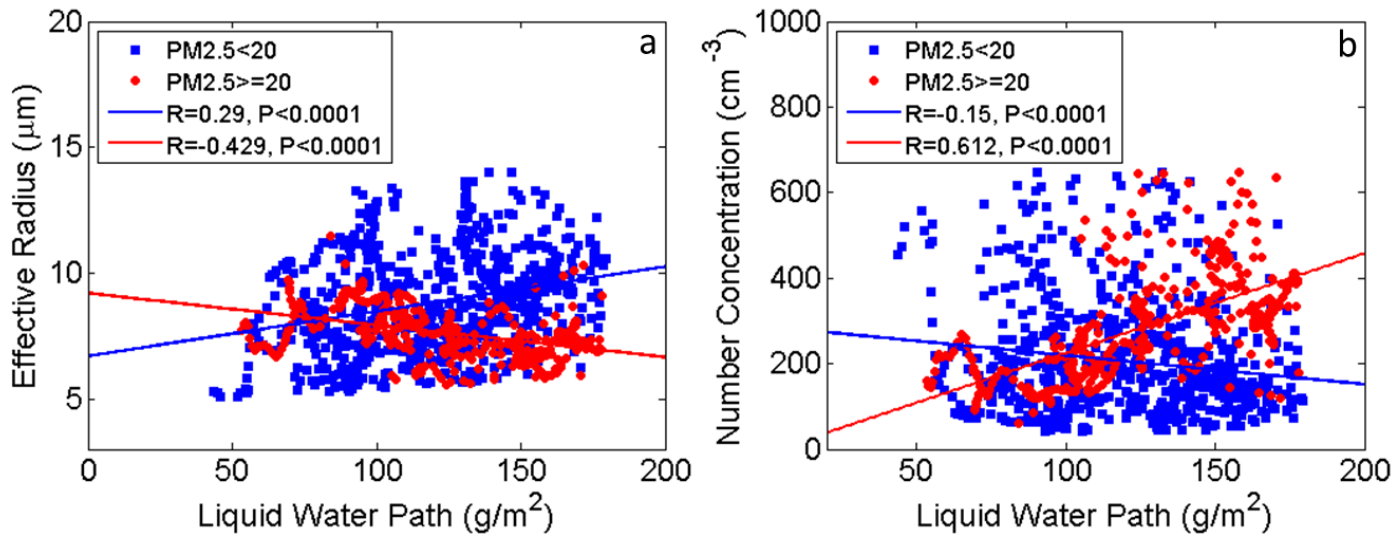

669 Fig. 6. (a) The relationship between Re and LWP under different PM2.5 value, and (b)

670 the relationship between cloud droplets number concentration and liquid water 671 path under different PM2.5 value.

672

673

674

675

676

677

678 
679

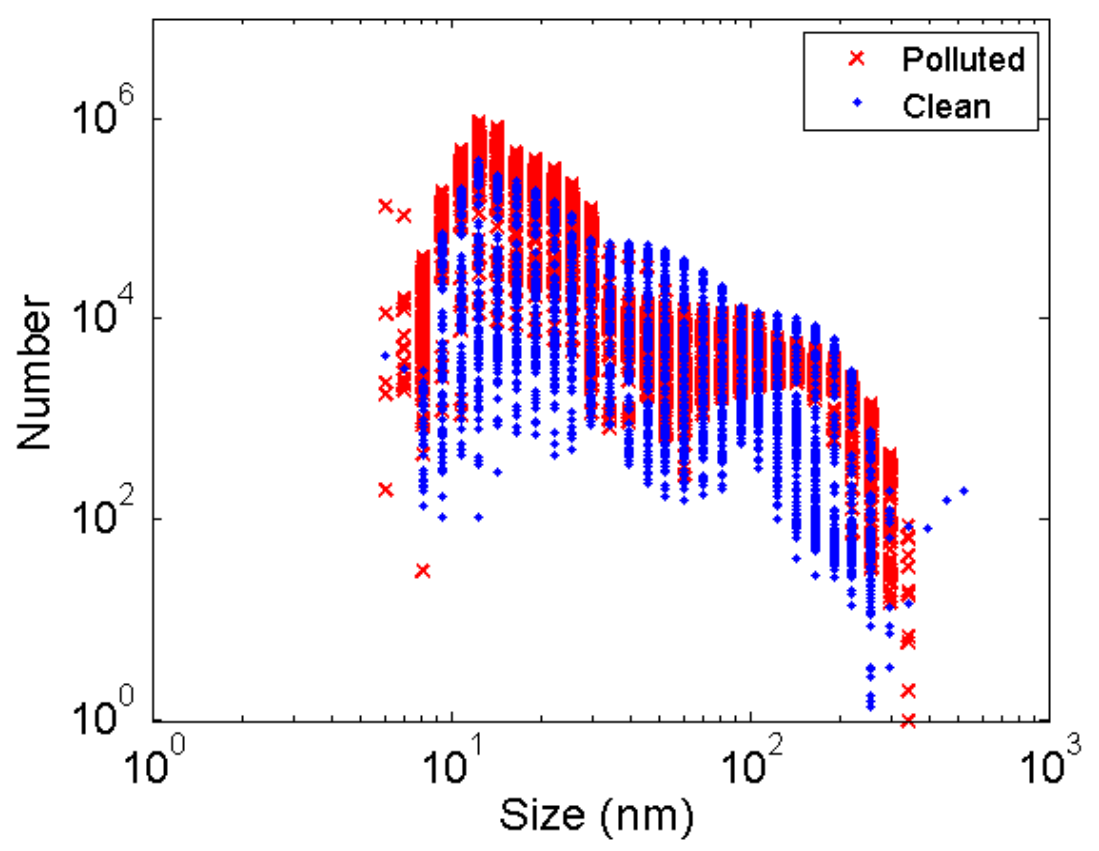

680 Fig. 7. FMPS measured aerosol size distribution on the polluted day (July $20^{\text {th }}, 2011$ )

681 and clean day (July $14^{\text {th }}, 2011$ ) during DISCOVER AQ field campaign.

682

683

684

685

686

687

688

689 


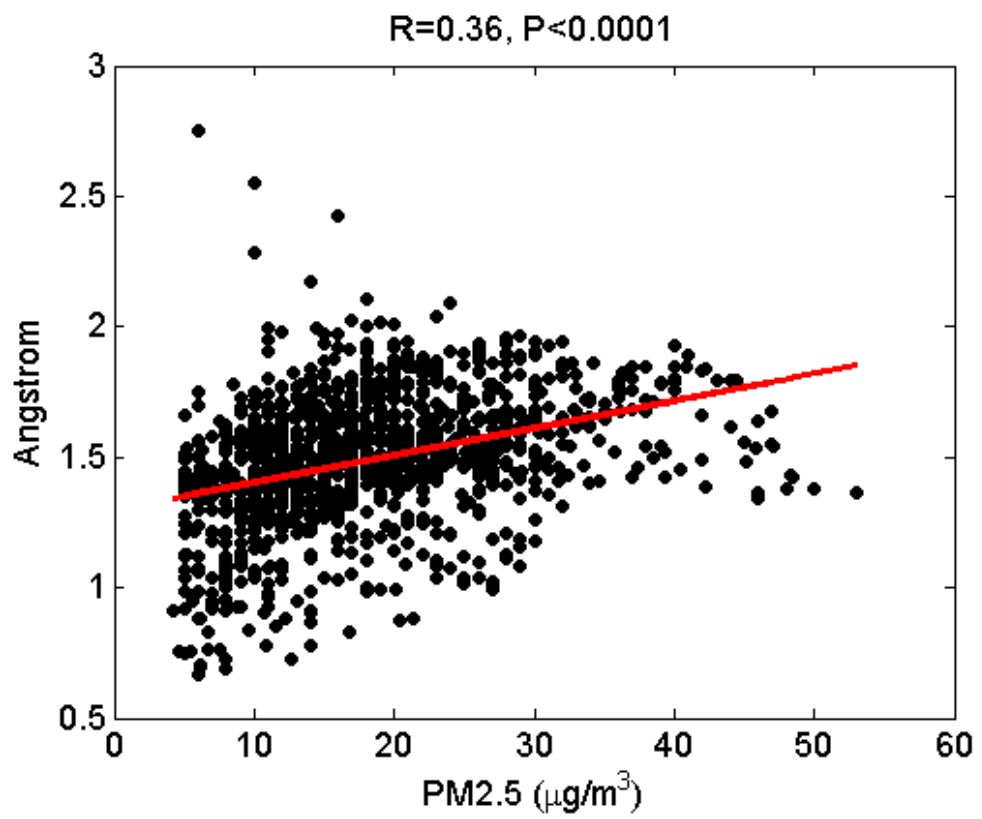

691 Fig. 8. The relationship of 5 years summer time hourly average Angstrom coefficient 692 and $\mathrm{PM} 2.5$. 